Dichtigkeit des interplanetarischen Raumes erkannt haben. Daher können wir die Hypothese des Herrn Professor v. Oppolzer nicht als dem wahren Sachverhalt entsprechend ansehen. Würde man mit dem Werthe $3 \times 10^{-16}$ die Hellig. keit der meteorischen Sonnencorona berechnen, so würde sich ergeben, dass dieselbe mehr als 500 mal diejenige des Vollmondes ubersteigt, was aber augenscheinlich nicht sein kann.
Ebenso lässt sich finden, dass die halbe grosse Axe der Erde jährlich um nicht mehr als 3 Millimeter, aber auch nicht weniger als 0.0003 Millimeter vermindert wird, so dass unser Planet nicht früher als nach $5 \times 10^{13}$ Jahren, aber auch nicht später als nach $5 \times 10^{17}$ Jahren, so weit vorgedrungen sein wird, dass er die Oberfläche der Sonne tangiren wird.

St. Petersburg 1885 April 6.

Foseph Kleiber.

\title{
Planeten- und Cometenbeobachtungen
}

angestellt von Herrn B. von Engelhardt am iz inch. Aequatoreal seiner Privatsternwarte in Dresden.

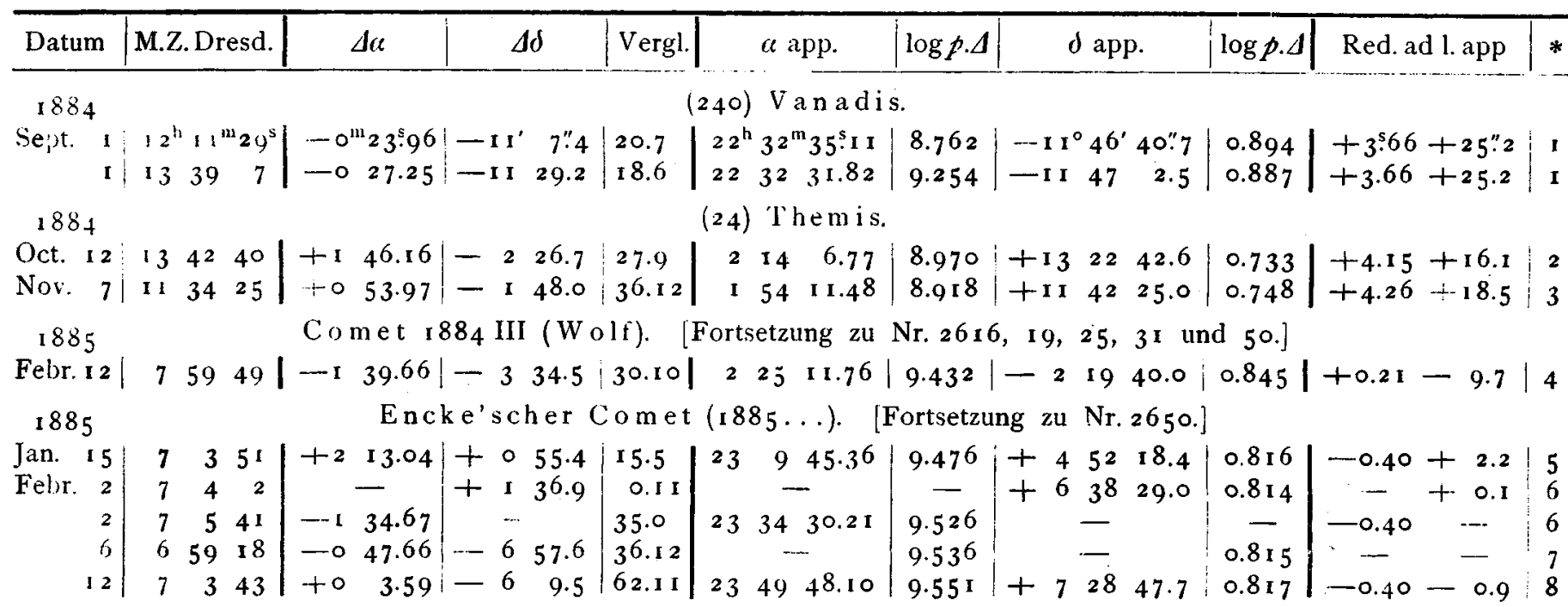

Angenomment mittlere Oerter der Vergleichsternefür den Anfang des Beobachtungsjahres.

\begin{tabular}{|c|c|c|c|c|c|c|c|}
\hline$\nLeftarrow$ & a (Wolfers) & $\delta$ (Auwers) & Autorität & 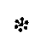 & $\alpha$ (Wolfers) & $\delta$ (Auwers) & Autorität \\
\hline $\mathbf{I}$ & 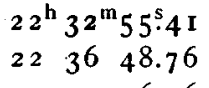 & $\begin{array}{r}-11^{\circ} 35^{\prime} 5^{8: 5} .5 \\
-113242.9\end{array}$ & $\begin{array}{l}\text { A. N. } 2659 \text { Anschl. an } \\
\text { A. N. } 69.104\end{array}$ & 6 & $23^{\mathrm{h}} 3^{6^{\mathrm{m}}} 5^{\mathrm{s}} \cdot 28$ & $+6^{\circ} 3^{6^{\prime}} 5^{2.0}$ & $\begin{array}{l}1 / 2\left(\text { BB.VI }+6^{\circ}{ }_{5} \times 83+\right. \\
\left.\text { Y. } 1045^{6}\right)\end{array}$ \\
\hline 2 & 2 I 216.46 & +132453.2 & $1 / 2\left(W_{1} 2^{h} I_{5} r+R \ddot{u} .586\right)$ & 7 & $234 I 24$ & +7 & DM. $+6^{\circ} 5201$ \\
\hline $\begin{array}{l}3 \\
4\end{array}$ & $\begin{array}{lll}1 & 53 & 13.25 \\
2 & 26 & 51.21\end{array}$ & 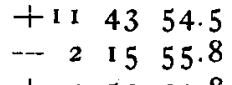 & $\begin{array}{l}\text { Glasgow } 429 \\
\text { Santini } 199\end{array}$ & 8 & 234944.9 I & $+7345^{8.1}$ & $\begin{array}{l}1 / 2\left(W_{1} 983+\text { Sant. } 272\right. \\
\text { und } 3 \text { I } 0)\end{array}$ \\
\hline 5 & $23 \quad 7 \quad 32.72$ & +45120.8 & $W_{1} 23^{h} 90$ & & & & \\
\hline
\end{tabular}

Vergleichung der Beobachtungen mit Ephemeriden (B-R).

(24) Themis Oct. $12 \Delta a=-0.19 \Delta \delta=-0.5$, Nov. $\Delta \alpha \alpha=-0.15 \Delta \delta=-$ I."o, Berliner Jahrbuch. Bemerkungen.

Comet 1884 III (Wolf).

Febr. 12. Dunstig, unruhig. Comet ziemlich schwach mit einem Kern 14. Grösse, welcher in der Nebelhülle etwas praec. steht.

Encke'scher Comet $(1885 \ldots)$.

Jan. 15. Der Comet ist sehr schwach, aber etwas heller als früher. Hisweilen zeigt sich eine hellere Stelle, ob aber dieselbe centrisch ist, konnte ich nicht entscheiden. Luft dunstig. Ich habe 1885 Febr. 6 den Vergleichstern an BB. VI $+4^{\circ} 498 \mathrm{I}$ angeschlossen; berücksichtigt man dieses, so wird die Cometenposition um +0.27 und +3.9 geändert. - Febr. 2 und 6 Comet hell, Febr. 12 sehr hell, wird aber bald nach Anfang der Beobachtung schwach "nd verwaschen. Der Comet hat ein körniges Aussehen, 2' Durchmesser und eine hellere Verdichtung, welche excentrisch etwas nach Norden liegt. Diese Beobachtungen des Encke'schen Cometen sind unsicher. In Folge einer Undeutlichkeit auf dem Registrirstreifen kann Febr. I 2 die Zeit der Beobachtung um $5^{\mathrm{m}}$ grösser sein, als oben angegeben ist, jedoch ist das wenig wahrscheinlich.

Dresden 1885 April 3. B. von Engelhardt. 